\title{
A EFETIVIDADE DOS DIREITOS HUMANOS E A CLÁUSULA DA RESERVA DO POSSÍVEL
}

\author{
THE EFFECTIVENESS OF HUMAN RIGHTS AND THE GRADUATED RESERVATION CLAUSES
}

Rogerio Taiar*

\begin{abstract}
Resumo:
O presente trabalho tem por objetivo investigar a efetividade dos Direitos Humanos, bem como o movimento de internacionalização desses direitos a partir do fim da Segunda Guerra Mundial. Será observado também o tratamento que a Constituição Federal de 1988 deu a esses direitos. Por fim, será estudado o significado da cláusula da reserva do possível e a possibilidade de se evocá-la como limite da efetividade dos Direitos Humanos.
\end{abstract}

Palavras-Chave: Efetividade. Direitos Humanos. Reserva do possível.

\begin{abstract}
:
The present work has for purpose to investigate the effectiveness of the human rights as well as the movement of internationalization of these rights from the end of World War II. The treatment will also be observed that the Federal Constitution of 1988 gave to these rights. Finally, it will be studied the meaning of the graduated reservation clauses and the possibility of if evoking it as limit of the effectiveness of the Human Rights.
\end{abstract}

Keywords: Effectiveness. Human Rights. Graduated reservation clauses.

Introdução

A questão dos Direitos Humanos, por mais estudada e lecionada que já tenha sido, é inextinguível, dada sua dinâmica de parceria com o ser humano, não importa onde ele esteja e a que tempo.

É uma questão que atravessa séculos e que se tornou mais clara e evidente justamente no confronto com seu total desrespeito - as duas grandes guerras mundiais. Mas a demanda pelo exercício de um direito também gera custos, organização social, que também devem ser arcados pelo conjunto dos que usufruem do direito - a sociedade organizada.

Nada mais justo: o fruidor do direito está também atrelado à geração de um contexto social próprio à sua fruição. O Estado, em especial nos regimes democráticos de direito, concentra as obrigações de planejamento, orçamento e execução de atos que resultem nesse "contexto propício" à fruição dos direitos fundamentais.

\footnotetext{
Doutor em Direitos Humanos pela Faculdade de Direito da Universidade de São Paulo. Professor de Direito Internacional do Instituto dos Advogados de São Paulo (IASP) e da Escola Superior Diplomática (ESD).
} 
Se a todo cidadão for garantido o exercício de seus direitos pelo simples fato de ter nascido, é natural concluir que nem todos serão, no entanto, contribuintes para a geração do contexto social a que nos referimos anteriormente. Mencione-se, como exemplo, as crianças, os inválidos, os idosos e fácil será deduzir que apenas parcela dos detentores dos direitos é também contribuinte para sua fruição.

Isso nos leva a mais uma conclusão inarredável: há um limite para o que a sociedade pode suportar por meio de seu representante, o Estado e esse limite vai seguramente impor aos gestores desse Estado a priorização, hierarquização, programação orçamentária e de tempo para satisfação dos cidadãos, o que fatalmente esbarrará em exceções e diversidade que serão levadas ao Judiciário para que decida o que é inadiável, ainda que excepcional, e está lastreado nas garantias dos direitos fundamentais.

É do que trata este trabalho, que parte de uma breve análise da evolução histórica do conceito e da efetivação dos direitos humanos, para então discutir os direitos sociais deles advindos e sua aplicação dentro da "reserva do possível", que envolve custos e recursos administrados pelo Estado.

1. Evolução histórica do conceito e efetividade dos Direitos Humanos

Os Direitos Humanos não eram reconhecidos como tal na Antiguidade, já que eles se impõem do jogo de interesses entre indivíduos/coletividade e Estado. No entanto, já a partir do Renascimento eles adquirem o fundamento do Direito Natural, evoluindo, nos séculos seguintes até o estabelecimento do Estado Moderno, no século XX. ${ }^{1}$

A modernidade foi palco das doutrinas privatista e liberal, até o surgimento e reformulação pelas doutrinas socialistas. Considere-se esse um período de "gestação" dos direitos e valores econômicos, culturais e sociais pelo viés "coletivo" e não mais do indivíduo. Mas o marco divisório que resultou na proteção internacional da pessoa humana, o que até então era reconhecido apenas "intramuros" das nações, foi o término da II Grande Guerra (1945). ${ }^{2}$

Mesmo não sendo de evolução linear e sucessiva, pode-se identificar três gerações de Direitos Humanos, de tal forma a dar-lhes uma classificação e visualização institucional da interação desses direitos nos cenários nacional e internacional, como sugere Vaz. ${ }^{3}$

\footnotetext{
VAZ, Anderson Rosa. A cláusula da reserva do financeiramente possível como instrumento de efetivação planejada dos direitos humanos econômicos, sociais e culturais. Revista de Direito Constitucional e Internacional, a. 15, n. 61, p. 26-27, out./dez. 2007.

2 Id. Ibid., p. 27.

3 Id. Ibid., p. 27.
} 
A primeira geração dos Direitos Humanos está representada pelos direitos individuais, políticos e de nacionalidade. São direitos cuja efetivação demanda a abstenção de ação estatal, ou seja, a interferência do Estado resulta, quase sempre, em prejuízo ou negação desses direitos. A segunda geração dos Direitos Humanos ganha a dimensão do social, cultural e econômico, sendo imperativo, para sua efetivação, a presença positiva do Estado. Tem-se que, se nos Direitos Humanos de primeira geração, a violação se dá pela atuação do Estado, nos de segunda geração, há que haver interferência, atuação estatal para sua efetivação, sendo sua omissão a violação dos mesmos. A terceira geração de direitos humanos diz respeito aos direitos difusos, transindividuais, supraindividuais ou metaindividuais. São os direitos resultantes e objetivos da organização internacional, como paz, desenvolvimento, meio ambiente, autodeterminação dos povos, proteção internacional ao consumidor e outros. ${ }^{4}$

Defende-se a historicidade desses direitos como fruto de uma elaboração, lutas e ações sociais, permitindo-se a reconstrução histórico-epistemológica dos Direitos Humanos. ${ }^{5} \mathrm{Ou}$, nas palavras de Bobbio:

Do ponto de vista teórico, sempre defendi - e continuo a defender, fortalecido por novos argumentos - que os direitos do homem, por mais fundamentais que sejam, são direitos históricos, ou seja, nascidos em certas circunstâncias, caracterizadas por lutas em defesa de novas liberdades contra velhos poderes, e nascidos de modo gradual, não todos de uma vez e nem de uma vez por todas. ${ }^{6}$

O Direito Humanitário é o que limita as ações humanas diante dos direitos humanos - também chamado Direito Internacional da Guerra, por regular a violência em âmbito internacional. A Liga das Nações, criada em 1920, é decorrência direta da constatação da urgência de se fixar padrões genéricos sobre paz e segurança mundial. Também a Organização Internacional do Trabalho (OIT), após a primeira Grande Guerra, é fruto desse espírito universal, que promove padrões internacionais de condições de trabalho e bem-estar. ${ }^{7}$

As três últimas referências - Direito Humanitário, Liga das Nações e OIT - configuram marcos históricos do início do processo de internacionalização dos direitos humanos, por representarem rupturas com o que até então se considerava, classicamente, a soberania nacional. É, no entanto, com o final da II Grande Guerra que os Direitos Humanos

\footnotetext{
VAZ, Anderson Rosa. A cláusula da reserva do financeiramente possível como instrumento de efetivação planejada dos direitos humanos econômicos, sociais e culturais. Revista de Direito Constitucional e Internacional, a. 15, n. 61, p. 26-27, out./dez. 2007. p. 27-28.

$5 \quad$ Id. Ibid., p. 29.

6 BOBBIO, Norberto. A era dos direitos. Rio de Janeiro: Campus, 1992. p. 41.

7 VAZ, Anderson R. op. cit., p. 29.
} 
ganham sedimentação internacional, ironicamente por deixar clara sua descontinuidade e necessidade de reestruturação no pós-guerra. ${ }^{8 / 9}$

A dissolução da Liga das Nações deu lugar à criação da Organização das Nações Unidas (1945), que adotou a Declaração Universal dos Direitos Humanos ${ }^{10}$ (Resolução 217 A, III) em assembléia geral realizada em 10 de dezembro de 1948, com a aprovação, por unanimidade, dos 48 Estados Membros.

É a partir desse documento que são redefinidos os postulados da Teoria do Estado, colocando o homem social no centro das preocupações contemporâneas. A instalação do Tribunal de Nuremberg, também instalado pelas Nações Unidas no pósguerra, consolidou a idéia da necessidade de limitação à soberania nacional, reconhecendo que os indivíduos tem direitos protegidos pelo direito internacional. Passaram a ser discutidos, no âmbito da ONU, assuntos como manutenção da paz, segurança internacional, desenvolvimento de relações amistosas entre Estados, cooperação internacional no plano econômico-social-cultural, a adoção de um padrão internacional para a saúde, o trabalho e o meio ambiente, reconhecidos como de interesse supranacional. ${ }^{11}$

ADeclaração Universal dos Direitos Humanos também afirma o compromisso das ordens nacional e internacional relativamente aos direitos civis, políticos, econômicos, sociais e culturais. Da experiência das duas Grandes Guerras resta o consenso sobre a necessidade de uma ética universal. A Declaração é o ápice de um processo que se iniciou com a Declaração de Independência dos Estados Unidos, a Declaração dos Direitos do Homem e do Cidadão e da Revolução Francesa; nesse processo, foram reconhecidos os direitos de igualdade essencial de todo ser humano em sua dignidade de pessoa, independentemente das diferenças de raça, cor, sexo, língua, religião, opinião, origem nacional ou social, riqueza ou quaisquer outras. ${ }^{12}$

Tem-se, pois, que "a efetivação dos direitos sociais depende da realização de políticas públicas por parte do Estado, o que faz com que a proteção de um direito social se dê pela ação estatal, e a violação pela omissão do poder público". ${ }^{13}$

\footnotetext{
PIOVESAN, Flávia. Direitos humanos e o direito constitucional internacional. 7. ed. São Paulo: Saraiva, 2007. p. 109.

VAZ, Anderson R. op. cit. p. 29.

10 Disponível em http://www.mj.gov.br/sedh/ct/legis_intern/ddh_bib_inter_universal.htm.

11 VAZ, Anderson R. op. cit. p. 30.

12 Id. Ibid., p. 30-31.

13 WANG, Daniel Wei Liang. Escassez de recursos, custos dos direitos e reserva do possível na jurisprudência do Supremo Tribunal Federal. Monografia. Sociedade Brasileira de Direito Público - Escola de Formação, 2006. p. 3.
} 


\section{Direitos Humanos e a Carta Magna de $1988^{14}$}

Nas palavras de Vaz, a "Constituição Federal de 1988 é uma das mais avançadas do mundo em relação à proteção dos direitos humanos" e a primeira brasileira a elencar o princípio da prevalência dos direitos humanos como fundamental às relações internacionais do Estado. ${ }^{15}$

A importância que se depreende do texto constitucional, relativamente aos Direitos Fundamentais, foi descrita de maneira irretocável pelo ministro Marco Aurélio Mello, que inclusive menciona seu papel hierárquico relativamente às cláusulas pétreas:

É preciso não perder de perspectiva que as emendas constitucionais podem revelar-se incompatíveis, também elas, com o texto da Constituição a que aderem. Daí a sua plena sindicabilidade jurisdictional, especialmente em face do núcleo temático protegido pela cláusula da imutabilidade inscrita no artigo 60, $\S 4^{\circ}$, da Carta Federal. As denominadas cláusulas pétreas representam, na realidade, categorias normativas subordinantes que, achando-se pré-excluídas, por decisão da Assembléia Nacional Constituinte, do poder de reforma do Congresso Nacional, evidenciam-se como temas insuscetíveis de modificação pela via do poder constituinte derivado (...)

Desse modo, não assiste ao Congresso Nacional qualquer poder de rever ou reapreciar o sistema de valores essenciais consagrado pela Constituição, na qual avultam, por sua indiscutível relevância, o postulado da Federação e o princípio tutelar dos direitos e garantias individuais, inclusive aqueles de índole jurídico-tributária.

Emendas à Constituição podem, assim, incidir, também, no vício da inconstitucionalidade, configurado este pela inobservância de limitações jurídicas superiormente estabelecidas no Texto Constitucional por deliberação do Órgão exercente das funções constituintes primárias ou originárias"16

(...)

Penso que a noção de cláusula pétrea é bem mais restrita do que a alusiva a direito e garantia previstos no Diploma Maior. O artigo 60, $\S 4^{\circ}$, inciso IV, é categórico no que veda deliberação sobre proposta de emenda que vise a abolir

14 Disponível em http://www.planalto.gov.br/ccivil_03/Constituicao/Constitui\%C3\%A7ao.htm.

15 VAZ, Anderson R. op. cit., p. 31.

16 MELLO, Marco Aurélio Mendes de Faria. Vencedor e vencido (seleção de notas e pronunciamentos no Supremo Tribunal Federal). Rio de Janeiro: Forense, 2006. p. 13. 
direito ou garantia constitucionais. Essa foi a premissa de meu voto. ${ }^{17}$

O termo "exercício dos direitos sociais e individuais" aparece já no preâmbulo à Constituição, que em seu art. $1^{\circ}$, II e III, reconhece a cidadania e a dignidade da pessoa humana como fundamentos da República Federativa do Brasil.

No art. $3^{\circ}$, a Carta Maior relaciona o que chama de "objetivos fundamentais da República Federativa do Brasil”, a saber, construir uma sociedade livre, justa e solidária (I); erradicar a pobreza (III); promover o bem de todos, sem preconceitos de origem, raça, sexo, cor, idade e quaisquer outras formas de discriminação (IV). ${ }^{18}$

$\mathrm{O}$ art. $4^{\circ}$ relaciona os princípios que norteiam as relações internacionais: independência nacional (I); prevalência dos direitos humanos (II); autodeterminação dos povos (III); não intervenção (IV); igualdade entre os Estados (V); defesa da paz (VI); solução pacífica dos conflitos (VII); repúdio ao terrorismo e ao racismo (VIII); cooperação entre os povos para o progresso da humanidade (IX) e concessão de asilo político (X). ${ }^{19}$

A Constituição Federal de 1988 classifica os direitos fundamentais em cinco grupos: (1) direitos individuais (art. ${ }^{\circ}$ 5); (2) direitos à nacionalidade (art. 12); (3) direitos políticos (arts. 14 a 17); (4) direitos sociais (arts. $6^{\circ}$ e 193 e ss); e (5) direitos solidários (arts. $3^{\circ}$ e 225 ).

Quanto aos Tratados Internacionais, existem quatro correntes de discussão do assunto, a saber: (a) hierarquia supraconstitucional dos tratados de direitos humanos (em função da supremacia da ordem internacional sobre a ordem nacional); (b) hierarquia constitucional (incorporação pelo texto constitucional dos direitos internacional); (c) hierarquia infraconstitucional, mas supralegal dos tratados (havendo conflito entre tratado e Constituição, esta prevalecerá; havendo antinomia envolvendo o tratado e lei federal, prevalece o primeiro); e (d) paridade hierárquica entre tratado e lei federal (desde 1977, o STF equipara o tratado federal à lei federal ${ }^{20}$ ).

Direitos humanos econômicos, sociais e culturais. A Rússia foi a primeira a reconhecer a importância desses direitos, em 1919, na Declaração dos Direitos do Povo Trabalhador e Explorado. Outras constituições passaram a também institucionalizar esses

\footnotetext{
7 Idem, Explicação, p. 18.

18 Constituição da República Federativa do Brasil, 1988, disponível em http://www.planalto.gov.br/ccivil_03/ Constituicao/Constitui $\% \mathrm{C} 3 \% \mathrm{~A} 7 \mathrm{ao} . \mathrm{htm}$

19 Id. Ibid.

20 Para um estudo mais aprofundado, v. VAZ, Anderson R. op. cit., p. 32-33; PIOVESAN, Flávia. op. cit. p. 74; MORAES, Guilherme Braga Pena. Dos direitos fundamentais: contribuição para uma teoria. São Paulo: LTr, 1997. p. 24 e ss.
} 
direitos, como a do México (1917), a da Alemanha (1919), a da Espanha (1931), a da Irlanda (1937) e outras. ${ }^{21}$

A promulgação da Declaração Universal de Direitos Humanos (1948), como já se mencionou alhures, reconhece expressamente a indivisibilidade entre direitos civis e políticos e direitos sociais, econômicos e sociais. Mesmo assim, foi só a partir de 1966 que a comunidade internacional passou a adotar o Pacto Internacional de Direitos Econômicos, Sociais e Culturais, que expande a relação de direitos sociais contida na Declaração Universal de Direitos Humanos. Tal Pacto cria obrigações para os Estados Membros, responsabilizando-os internacionalmente pelos casos de violação de direitos econômicos, sociais e culturais contidos em seu texto. ${ }^{22}$

Enquanto os direitos civis e políticos são assegurados de imediato, por serem auto-aplicáveis, os direitos econômicos, sociais e culturais dependem da criação de "condições, ou seja, sua efetivação deve ser programada e progressiva". Com a criação do Comitê de Direitos Econômicos e Culturais das Nações Unidas, cuja competência é a de monitorar a implementação dos direitos elencados no Pacto, os Estados Membros devem demonstrar, através de relatórios, as medidas tomadas, assim como as dificuldades encontradas para a efetivação dos citados direitos. ${ }^{23}$

Relativamente aos direitos sociais, mencione-se a importância do Protocolo Adicional à Convenção Americana sobre Direitos Humanos em Matéria de Direitos Econômicos, Sociais e Culturais (Protocolo de San Salvador, 1988), que reforça, na esfera do Sistema Interamericano de Direitos Humanos o reconhecimento dos direitos humanos de segunda geração, a saber: direito ao trabalho (art. $6^{\circ}$ ); direitos sindicais (art. $8^{\circ}$ ); direito à previdência social (art. $9^{\circ}$ ); direito à saúde (art. $10^{\circ}$ ); direito a um meio ambiente sadio (art. 11); direito à alimentação (art. 12); direito à educação (art. 13); direito aos benefícios da cultura (art. 14); direitos à constituição e proteção da família (art. 15); direito da criança (art. 16); direito do idoso (art. 17); e direito ao portador de deficiência (art. 18). ${ }^{24}$

No Brasil, a Constituição de 1988 representa a maior conquista em termos de direitos sociais. Tais direitos são citados também a partir do Preâmbulo da CF-88 e seguem especificados no decorrer de seu texto, como menciona-se a seguir.

$\mathrm{O}$ art. $1^{\circ}$ da CF-88 institui os "valores sociais do trabalho" como fundamento da República Federativa do Brasil; o art. $3^{\circ}$ funda a "sociedade solidária", o "desenvolvimento nacional", a erradicação da "pobreza e marginalização" e a redução

\footnotetext{
21 VAZ, Anderson Rosa. A cláusula da reserva do financeiramente possível como instrumento de efetivação planejada dos direitos humanos econômicos, sociais e culturais. Revista de Direito Constitucional e Internacional, a. 15, n. 61, p. 26-27, out./dez. 2007. p. 34.

22 Id. Ibid., p. 35.

23 Id. Ibid.

24 Id. Ibid., p. 36.
} 
das "desigualdades sociais e regionais" como objetivos fundamentais da República; o art. $4^{\circ}$, como se viu alhures, relaciona os princípios que regem a Nação em suas relações internacionais; o art. $5^{\circ}$ é o que garante os direitos individuais; o art. $6^{\circ}$ se refere a educação, saúde, trabalho, moradia, lazer, segurança, previdência social, proteção à maternidade e à infância, além da assistência aos desamparados; o art. $7^{\circ}$ estabelece direitos e garantias de trabalho digno; o art. 43 prevê a possibilidade de articulação, pelo Estado, de uma ação em um complexo geoeconômico e social, com o objetivo de seu desenvolvimento e redução de desigualdades regionais; os arts. 127 a 135 estabelecem o Ministério Público e a Advocacia como funções essenciais aos interesses sociais; o art. 170 cria a ordem econômica, dispondo sobre: a função social da propriedade (II), a defesa do consumidor (V), a defesa do meio ambiente (VI), a redução de desigualdades regionais e sociais (VII), a busca do pleno emprego (VIII); o art. 182 trata da política de desenvolvimento urbano; o art. 184 trata do dever-poder de desapropriação, pela União, dos imóveis rurais que não cumpram sua função social; o art. 192 funda o sistema financeiro nacional com vistas a atender os interesses da coletividade. ${ }^{25}$

Sob o Título VIII da CF-88, institui-se a "Ordem Social" com base no primado do trabalho e objetivando o bem-estar e a justiça sociais (art. 193). Ainda nesse título, a Carta Maior garante efetividade e proteção: da seguridade social (arts. 194 e 195); da saúde (arts. 196 a 200); da previdência e assistência social (arts. 201 a 204); da educação (arts. 205 a 214); da cultura (arts. 215 e 216); do desporto (art. 217) da ciência e tecnologia (arts. 218 e 219); da comunicação social (arts. 220 a 224); o meio ambiente (art. 225); da família, da criança, do adolescente e do idoso (arts. 226 e 230); dos índios (arts. 231 e 232). ${ }^{26}$

$\mathrm{O}$ art. $5^{\circ}$ da CF-88 dispõe que todos os direitos são de exigibilidade imediata $\left(\S 1^{\circ}\right)$, inclusive os direitos humanos econômicos, sociais e culturais. Para a garantia de padrões mínimos de vida digna para todos, exige-se do Poder Público que este estabeleça estratégias políticas de efetivação desses direitos. Há que se mencionar, no entanto, que tal efetivação demanda recursos financeiros, já que não se concretizam sem ações afirmativas por parte do Estado, da sociedade civil e da sociedade internacional - ações essas que dependem de recursos orçamentários. O argumento de falta desses recursos ou sua escassez tem sido utilizado seguidamente por nossos administradores públicos, o que resulta no adiamento da plena realização dos Direitos Humanos, Econômicos, Sociais e Culturais. ${ }^{27}$

\footnotetext{
25 VAZ, Anderson Rosa. A cláusula da reserva do financeiramente possível como instrumento de efetivação planejada dos direitos humanos econômicos, sociais e culturais. Revista de Direito Constitucional e Internacional, a. 15 , n. 61 , p. 26-27, out./dez. 2007 . p. 36-37.

26 Id. Ibid., p. 38.

27 VAZ, Anderson Rosa. A cláusula da reserva do financeiramente possível como instrumento de efetivação
} 
Observando-se que o Pacto Internacional de DHESC é de 1966, e o Protocolo de San Salvador é de 1988, fácil concluir que não se pode mais alegar falta de recursos para a efetivação de tais direitos. Mencione-se, também, que o Estado de Direito tem, como pressuposto essencial, a realização de um Estado Orçamentário, que significa o equilíbrio entre receitas e despesas, sendo o orçamento o instrumento próprio a esse balanço. A alegação de falta de recursos para a efetivação dos direitos econômicos, sociais e culturais realça dois erros: o desrespeito aos direitos humanos e o desrespeito às normas constitucionais de planejamento orçamentário. ${ }^{28}$

De acordo com o art. 100, $\S 1^{\circ}$-A da Constituição Federal, "é obrigatória a inclusão no orçamento das entidades de direito público, de verba necessária ao pagamento de seus débitos oriundos de sentenças transitadas em julgado, constantes de precatórios judiciários, apresentados até $1^{\circ}$ de julho, fazendo-se o pagamento até o final do exercício seguinte...".

\section{Reserva do possível, custo dos direitos e escassez dos recursos}

A partir da constatação de que decisões judiciais podem impactar as finanças do Estado e resultar em priorização da aplicação dos recursos públicos (sabidamente escassos), alguns teóricos lembram que há um limite fático à exigibilidade judicial dos direitos sociais. Tal limite seria a dependência econômica do Estado (cobertura orçamentária), que se expressa em decisões judiciais pelo termo "reserva do possível". ${ }^{29}$

Tal expressão foi difundida por decisão da Corte Constitucional alemã, proferida em 1972, conhecida como Numerus Clausus, tratando a validade da limitação de vagas em universidades públicas, tendo em vista a pretensão de ingresso de um número maior de candidatos. A Constituição alemã não consagra o direito fundamental à educação, mas o Tribunal Constitucional entendeu que a liberdade de escolha profissional exigia, de certa forma, o direito de acesso ao ensino universitário. Como se vê, pode-se desdobrar a visão de "reserva do possível" em dois componentes: um fático e um jurídico. O componente fático relaciona-se à efetiva disponibilidade de recursos necessários à satisfação do direito prestacional, enquanto o componente jurídico depende de existência de autorização orçamentária para o Estado incorrer nos respectivos custos. ${ }^{30}$

planejada dos direitos humanos econômicos, sociais e culturais. Revista de Direito Constitucional e Internacional, a. 15, n. 61, p. 26-27, out./dez. 2007. p. 39.

28 Id. Ibid., p. 39-40.

29 WANG, Daniel W. L. op. cit., p. 4.

30 SARMENTO, Daniel. A proteção judicial dos direitos sociais: alguns parâmetros ético-jurídicos. In: SARMENTO, Daniel; SOUZA NETO, Cláudio Pereira de (Orgs.). Direitos sociais: fundamentos, justiciabilidade e direitos concretos. Rio de Janeiro: Ed. Lúmen Júris (no prelo). A utilização dos dados contidos neste artigo foi gentilmente permitida pelo autor. 
Como mencionado anteriormente, a efetivação dos Direitos Sociais é dependente de provisão orçamentária, sendo inquestionável ser esta a primeira exigibilidade imediata dos DHESC: a previsão nas leis orçamentárias. Há, porém, que se discutir o tema da reserva do possivel, diferenciando-o, primeiramente, da reserva do financeiramente possivel. A primeira é gênero, de que a segunda é espécie. A reserva do possível está relacionada a todos os eventos formais ou materiais que impedem a efetivação dos DHESC e a reserva do financeiramente possivel refere-se apenas aos limites orçamentários do Estado. $^{31}$

Tem-se como aceitável a reserva do possivel, mesmo em nome dos direitos humanos, quando da contingência de fatos da vida (a descontinuação da fabricação de determinado medicamento, por exemplo). Não é o caso da reserva do financeiramente possível, que toca na destinação de recursos públicos, o que é legitimamente estabelecido pelos poderes Legislativo e Executivo. Mesmo em vista da relevância econômica do objeto dos direitos sociais prestacionais, este é o posicionamento que tem prevalecido.

Veja-se a Ementa de deliberação do Supremo Tribunal Federal, indeferindo o pedido de Intervenção Federal 2.915-5, requerida no Estado de São Paulo, motivada pelo não-pagamento de precatórios judiciais:

Ementa: Intervenção federal. 2. Precatórios judiciais. 3. Não configuração de atuação dolosa e deliberada do Estado de São Paulo com finalidade de não pagamento. 4. Estado sujeito a quadro de múltiplas obrigações de idêntica hierarquia. Necessidade de garantir eficácia a outras normas constitucionais, como, por exemplo, a continuidade de prestação de serviços públicos. 5. Aintervenção, como medida extrema, deve atender à máxima da proporcionalidade. 6 . Adoção da chamada relação de precedência condicionada entre princípios constitucionais concorrentes. 7. Pedido de intervenção indeferido." (IF 2.915-SP, rel. Min. Marco Aurélio; red. p/ acórdão Min. Gilmar Mendes; j. 03.02.2003 - Tribunal Pleno - DJ 28.11.2003). ${ }^{32}$

A posição do ministro Celso de Mello sobre o mesmo assunto ilustra com clareza os limites encontrados pelo Judiciário para a intervenção federal:

É que a realização dos direitos econômicos, sociais e culturais - além de caracterizar-se pela gradualidade de seu processo de concretização - depende, em grande medida, de um inescapável vínculo financeiro subordinado às possibilidades orçamentárias do Estado, de tal modo que, comprovada, objetivamente, a incapacidade econômico-financeira da

\footnotetext{
31 VAZ, Anderson R. op. cit., p. 40.

32 Apud Id. Ibid., p. 42.
} 
pessoa estatal, desta não se poderá razoavelmente exigir, considerada a limitação material referida, a imediata efetivação do comando fundado no texto da Carta Política.

(...)

- Vê-se, pois, que os condicionamentos impostos, pela cláusula da "reserva do possível", ao processo de concretização dos direitos de segunda geração - de implantação sempre onerosa -, traduzem-se em um binômio que compreende, de um lado, (1) a razoabilidade da pretensão individual/social deduzida em face do Poder Público e, de outro, (2) a existência de disponibilidade financeira do Estado para tornar efetivas as prestações positivas dele reclamadas.

Desnecessário acentuar-se, considerado o encargo governamental de tornar efetiva a aplicação dos direitos econômicos, sociais e culturais, que os elementos componentes do mencionado binômio (razoabilidade da pretensão + disponibilidade financeira do Estado) devem configurar-se de modo afirmativo e em situação de cumulativa ocorrência, pois, ausente qualquer desses elementos, descaracterizar-se-á a possibilidade estatal de realização prática de tais direitos." (ADPF 45 MC/DF/2004, rel. Min. Celso de Mello). ${ }^{33}$

Observa-se, pois, que a ausência ou escassez de recursos materiais constitui barreira à efetivação dos direitos sociais, de tal maneira que o cidadão que pleiteia um direito social ao Estado, que, por sua vez, alega falta de recursos financeiros e ausência de previsão orçamentária, terá negado pelo Judiciário seu pedido, aniquilando direitos humanos consagrados na ordem interna e externa. Ora, a cláusula de reserva do possível deveria condicionar a efetivação dos direitos humanos econômicos, sociais e culturais, não sua negativa. A CF-88 tanto prevê a realização de um Estado Orçamentário, como estabelece o orçamento como instrumento de concretização desse equilíbrio. ${ }^{34}$

Não se trata de exigir prestação estatal desatrelada dos limites orçamentários, já que a própria Declaração Universal dos Direitos Humanos aventa a vinculação da efetivação dos direitos humanos econômicos, sociais e culturais à organização e recursos de cada país. O que se tem exigido é que o Estado comprove o tratamento que o direito social lesado está recebendo para sua superação, tanto no passado, quanto no presente e no futuro. ${ }^{35}$

\footnotetext{
33 VAZ, Anderson Rosa. A cláusula da reserva do financeiramente possível como instrumento de efetivação planejada dos direitos humanos econômicos, sociais e culturais. Revista de Direito Constitucional e Internacional, a. 15 , n. 61 , p. 26-27, out./dez. 2007. p. 42-43.

34 Id. Ibid., p. 44-45.

35 VAZ, Anderson Rosa. A cláusula da reserva do financeiramente possível como instrumento de efetivação
} 
A escassez de recursos demanda do Estado escolhas - ou preferências - o que, por sua vez, pressupõe preteridos. Trata-se, aqui, portanto, da possibilidade (direito) dos preteridos buscarem, por meio do Judiciário, a tutela de seus direitos. ${ }^{36}$

Ainda que muito se tenha avançado na seara dos DHESC no país, as intervenções judiciais eram raras, sendo a posição do Judiciário francamente ortodoxa frente ao princípio da separação dos poderes. Consideravam-se indevidas as intervenções judiciais que implicassem controle sobre políticas públicas voltadas para a efetivação dos direitos sociais, seara ocupada pelos poderes Legislativo e Executivo. Atualmente, tem-se uma nova visão sobre o assunto e tornaram-se comuns as decisões judiciais que determinam a entrega de prestações materiais relacionadas a direitos sociais constitucionalmente positivados aos jurisdicionados. ${ }^{37}$

É preciso levar em consideração também, como bem lembrado por Sarmento, que o acesso à justiça no Brasil não é, absolutamente, igualitário. Por inúmeras razões, há um descompasso entre os segmentos mais excluídos e as camadas mais bem aquinhoadas financeiramente, o que reflete um paradoxo, já que o ativismo judicial em matéria de direitos sociais - supostamente voltados para a promoção da igualdade material - pode contribuir para a concentração da riqueza, com a canalização de recursos públicos escassos para os setores da população já mais beneficiada socialmente. ${ }^{38}$

Se a fruição de direitos básicos por todos os cidadãos é um dos pressupostos da democracia, a ausência dessa situação ou a presença de um nível intolerável de desigualdade social, comprometem a condição a condição de "agentes morais independentes dos cidadãos e ainda prejudicam a possibilidade de que se vejam como parceiros livres e iguais na empreitada comum de construção da vontade política da sociedade". ${ }^{39}$

Saliente-se que a garantia dos direitos sociais não se esgota numa tarefa jurídica, envolvendo um emaranhado de ações estatais, que compreende desde a formulação de políticas públicas, a criação de procedimentos, até o dispêndio de recursos e outras atividades não afeitas ao Judiciário.

planejada dos direitos humanos econômicos, sociais e culturais. Revista de Direito Constitucional e Internacional, a. 15, n. 61, p. 26-27, out./dez. 2007. p. 45.

36 WANG, Daniel W. L. op. cit., p. 3.

37 SARMENTO, Daniel. op. cit. A utilização dos dados contidos neste artigo foi gentilmente permitida pelo autor.

38 Id. Ibid.

39 Id. Ibid. 


\section{Considerações finais}

A análise dos textos pesquisados para este trabalho aponta, em primeiro lugar, para a dimensão histórica e evolutiva dos direitos humanos. Não se trata de evolução linear, mas dependente de inúmeros fatores sociais.

No caso brasileiro, a Constituição Federal de 1988 recepcionou de maneira francamente favorável os direitos humanos internacionais e a jurisprudência deu um importante passo ao reconhecer a plena justiciabilidade dos direitos sociais. No entanto, ainda se verificam barreiras de ausência ou escassez de recursos para sua efetivação, especialmente os financeiros.

O que não se pode aceitar é que a simples alegação das limitações existentes para a efetivação dos direitos sociais seja motivo bastante para isentar o Estado de suas obrigações, tendo em vista a programação orçamentária que deve prover recursos para a efetivação progressiva e previsível desses direitos.

Em concordância com Sarmento, ${ }^{40}$ entendemos que, se já foi vencido, e com sucesso, o momento de afirmação da sindicabilidade dos direitos prestacionais, estamos vivenciando a fase de racionalização deste processo, que passa, ainda segundo o mesmo autor, por dois pontos principais: (1) a superação da "euforia judicialista" que tomou conta dos meios jurídicos brasileiros, com o reconhecimento de que o Poder Judiciário, apesar da relevância de sua função, não é e não tem como ser, por limitações institucionais, o protagonista no cenário da afirmação dos direitos sociais, muito mais dependentes de políticas públicas formuladas e implementadas pelo Legislativo e Executivo e da mobilização da sociedade civil; e (2) o traçado de parâmetros ético-jurídicos para as intervenções judiciais nessa seara.

Há necessidade de mudança nos padrões sociais brasileiros, que ainda refletem grandes desigualdades, para redirecionar os direitos sociais para seu verdadeiro propósito, que a promoção da inclusão social dos excluídos.

São Paulo. março de 2009.

Referências

BOBBIO, Norberto. A era dos direitos. Rio de Janeiro: Campus, 1992.

40 SARMENTO, Daniel. A proteção judicial dos direitos sociais: alguns parâmetros ético-jurídicos. In: SARMENTO, Daniel; SOUZA NETO, Cláudio Pereira de (Orgs.). Direitos sociais: fundamentos, justiciabilidade e direitos concretos. Rio de Janeiro: Ed. Lúmen Júris (no prelo). A utilização dos dados contidos neste artigo foi gentilmente permitida pelo autor. 
BRASIL. Constituição da República Federativa do Brasil de 1988, consultada em 8/6/08. Disponível em: http://www.planalto.gov.br/ccivil_03/Constituicao/Constitui\%C3\%A7ao.htm.

DECLARAÇÃO UNIVERSAL DOS DIREITOS HUMANOS, consultada em 08 de junho de 2008, disponível em: http://www.mj.gov.br/sedh/ct/legis_intern/ddh_bib_inter_universal.htm.

MELLO, Marco Aurélio Mendes de Faria. Vencedor e vencido (seleção de notas e pronunciamentos no Supremo Tribunal Federal). Rio de Janeiro: Forense, 2006.

PIOVESAN, Flávia. Direitos humanos e o direito constitucional internacional. 7. ed. São Paulo: Saraiva, 2007.

SARMENTO, Daniel. A proteção judicial dos direitos sociais: alguns parâmetros ético-jurídicos. In: SARMENTO, Daniel; SOUZA NETO, Cláudio Pereira de (Orgs.). Direitos sociais: fundamentos, justiciabilidade e direitos concretos. Rio de Janeiro: Ed. Lúmen Júris (no prelo).

VAZ, Anderson Rosa. A cláusula da reserva do financeiramente possível como instrumento de efetivação planejada dos direitos humanos econômicos, sociais e culturais. Revista de Direito Constitucional e Internacional, a. 15, n. 61, out./dez. 2007.

WANG, Daniel Wei Liang. Escassez de recursos, custos dos direitos e reserva do possível na jurisprudência do Supremo Tribunal Federal. Monografia. Sociedade Brasileira de Direito Público - Escola de Formação, 2006. 